\title{
Dorsal Thoracic Arachnoid Web and the "Scalpel Sign": A Distinct Clinical-Radiologic Entity
}

\author{
M.A. Reardon, P. Raghavan, K. Carpenter-Bailey, S. Mukherjee, J.S. Smith, J.A. Matsumoto, C.-P. Yen, \\ M.E. Shaffrey, R.R. Lee, C.I. Shaffrey, and M. Wintermark
}

\begin{abstract}
SUMMARY: Arachnoid webs are intradural extramedullary bands of arachnoid tissue that can extend to the pial surface of the spinal cord, causing a focal dorsal indentation of the cord. These webs tend to occur in the upper thoracic spine and may produce a characteristic deformity of the cord that we term the "scalpel sign." We describe 14 patients whose imaging studies demonstrated the scalpel sign. Ten of 13 patients who underwent MR imaging demonstrated T2WI cord signal-intensity changes, and 7 of these patients also demonstrated syringomyelia adjacent to the level of indentation. Seven patients underwent surgery, with 5 demonstrating an arachnoid web as the cause of the dorsal indentation demonstrated on preoperative imaging. Although the webs themselves are rarely demonstrated on imaging, we propose that the scalpel sign is a reliable indicator of their presence and should prompt consideration of surgical lysis, which is potentially curative.
\end{abstract}

$S^{2}$ pinal arachnoid webs are rarely discussed entities, with only 6 reported cases in the neurosurgical literature. ${ }^{1-3}$ These webs represent an intradural extramedullary transverse band of arachnoid tissue that extends to the dorsal surface of the spinal cord, causing mass effect and dorsal indentation. In each of the cases reported, a syringomyelia was present above or below the level of cord indentation. The author of one of the cases reported visualization of an arachnoid band on preoperative MR imaging. ${ }^{3}$

We present a series of cases that demonstrates a characteristic focal dorsal indentation of the upper thoracic spinal cord, coined the "scalpel sign" because of the resemblance on sagittal MR imaging and CT myelographic images to a scalpel with its blade pointing posteriorly (Fig 1). We propose that the presence of an arachnoid web in the dorsal subarachnoid space can result in progressive alterations of the CSF flow dynamics and eventually lead to syringomyelia. MR imaging and CT myelography currently lack the resolution to consistently identify these thin webs of tissue. However, recognition of a reliable secondary imaging finding, the scalpel sign, can suggest the presence of an arachnoid web,

Received June 13, 2012; accepted after revision July 12.

From the Neuroradiology Division, Department of Radiology (M.A.R., P.R., K.C.-B., S.M., J.A.M., M.W.) and Department of Neurosurgery (J.S.S., C.-P.Y., M.E.S., C.I.S.), University of Virginia, Charlottesville, Virginia; and Department of Radiology (R.R.L.), Veterans Administration San Diego Healthcare System and University of California, San Diego, San Diego, California.

Drs Reardon and Raghavan were co-first authors.

Please address correspondence to Prashant Raghavan, MBBS, Department of Radiology and Medical Imaging, Division of Neuroradiology, University of Virginia, PO Box 800170, Charlottesville, VA 22908-0170; e-mail: Pr9k@virginia.edu

http://dx.doi.org/10.3174/ajnr.A3432 allowing proper neurosurgical referral and potentially curative treatment.

\section{CASE SERIES}

This report is a retrospective review of 14 patients demonstrating a focal dorsal indentation in the upper thoracic spinal cord (Fig 2). The age range was 31-67 years, with a 9:5 female/male ratio. Presenting symptoms included back pain and upper and lower extremity weakness and numbness (Table). All 14 patients demonstrated a characteristic scalpel-shaped deformity of the upper thoracic cord on MR imaging or CT myelography. Seven patients demonstrated both increased T2WI signal in the spinal cord and syringomyelia adjacent to the level of dorsal indentation. Three patients demonstrated only increased T2WI cord signal adjacent to the level of dorsal indentation. Seven patients underwent surgery following their imaging studies. In 2 surgical cases, only a myelotomy was performed to decompress the syringomyelia and an arachnoid web was not sought. The 5 cases with surgical confirmation of an arachnoid web are described below.

\section{Case 1}

A 51-year-old woman presented with an 8-year history of low back pain and 1 year of intermittent midback pain and bilateral shoulder pain. She did not have radicular pain or numbness, and there was no history of trauma or spinal surgery. MR imaging demonstrated a focal indentation along the dorsal surface of the spinal cord at the T4 vertebral body level (Fig 3). Increased T2WI signal with cord expansion and syringomyelia extended from T1 to T3. Cord signal inferior to the focal deviation was normal. A 

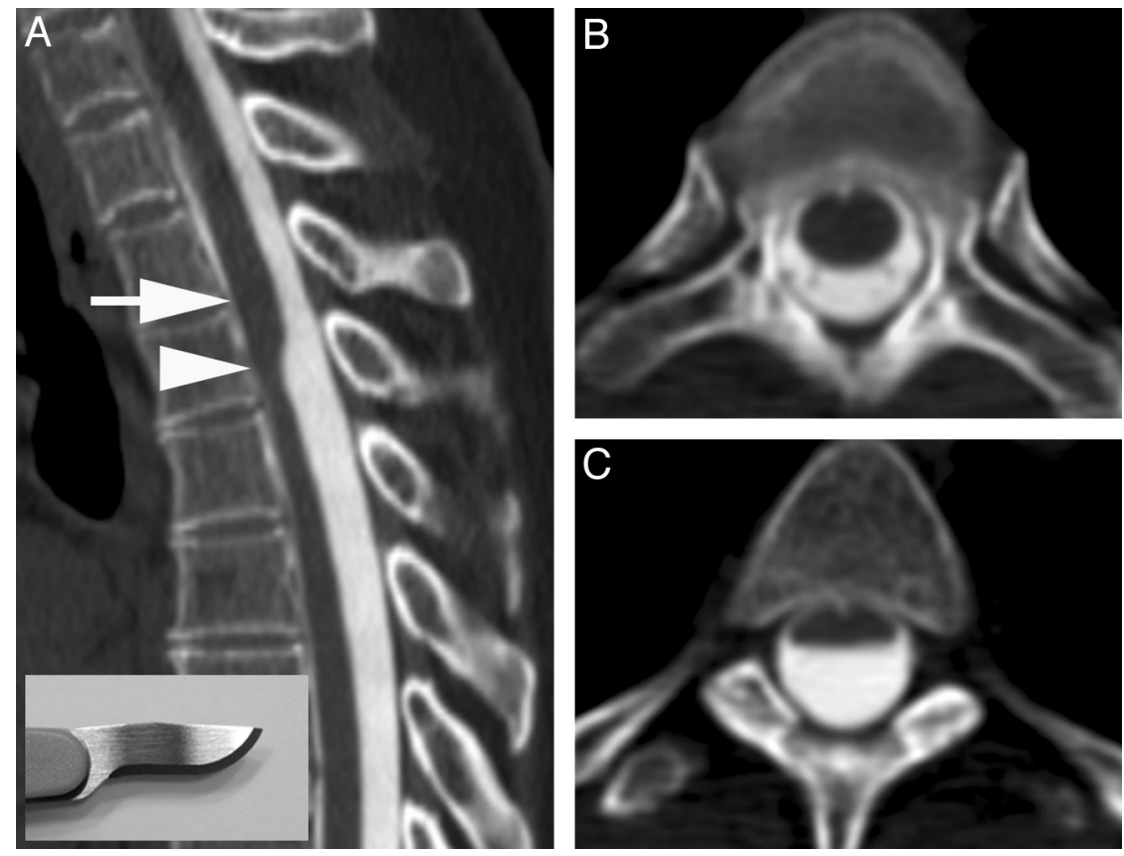

FIG 1. A, CT myelogram demonstrates the scalpel sign with the characteristic focal dorsal indentation of the upper thoracic spinal cord. An insert of a scalpel shows how the dorsal indentation relates to the pointed edge of the blade. $B$, Corresponding axial image above the level of dorsal indentation (level of the arrow in A). C, Corresponding axial image at the level of dorsal indentation (level of the arrowhead in A).

significant amount of posterior epidural fat was not directly compressing the cord. It was hypothesized that the appearance of the spinal cord deviation was secondary to an arachnoid web. The patient underwent T2-T4 laminectomies for intradural exploration, which revealed kinking of the spinal cord caused by a transverse dorsal arachnoid web at the level of the narrowing. The web was carefully sectioned with visually apparent relief of the kinking. Follow-up MR imaging revealed resolution of the focal cord indentation, decreased T2WI signal abnormality, and resolution of the syringomyelia. The patient reported an improvement in her upper back and shoulder pain but continued to have chronic low back pain.

\section{Case 2}

A 56-year-old woman was admitted with a 15-year history of episodic lower extremity weakness. Physical examination demonstrated spastic paraparesis with hyper-reflexia, clonus, and hypertonia. She underwent a complete work-up for demyelinating diseases, of which the findings were negative. There was no history of trauma or spinal surgery. MR imaging of the thoracic spine demonstrated focal dorsal indentation of the spinal cord at the T3 vertebral body level. Immediately cephalad to the indentation, there was T2WI cord-signal abnormality and syringomyelia. CT myelography demonstrated the same findings, and there was no evidence of an arachnoid cyst or ventral spinal cord herniation. Subsequently, T3-T4 laminectomies were performed, and a thickened arachnoid membrane was removed. Two-month postoperative imaging demonstrated resolution of the cord indentation and syringomyelia (Fig 4). The patient reported greatly improved function and comfort in her lower extremities.

\section{Case 3}

A 56-year-old woman initially presented with gait instability and bilateral lower extremity weakness. There was no history of trauma or spinal surgery. Imaging revealed an upper thoracic syrinx, which was initially treated at an outside institution with a T6 laminectomy and drainage of the syrinx. The initial surgery did not relieve the patient's symptoms, which progressively worsened. Two years later, she presented to our institution, and a CT myelogram revealed spinal cord expansion from T6 through T8 and a dorsal indentation of the spinal cord rostral to these levels. Subsequently, the patient underwent laminectomies at T5, T7, T8, and T9. A thickened arachnoid membrane was encountered in the dorsal subarachnoid space rostral to the level of a syrinx. The membrane was removed, and the syrinx was fenestrated. Pathologic examination demonstrated a simple arachnoid membrane. In the immediate postoperative period, the patient noted increased sensation and decreased pain in her lower extremities. Her symptoms continued to improve on follow-up visits. Follow-up MR imaging demonstrated resolution of the dorsal indentation and cord expansion.

\section{Case 4}

A 45-year-old man presented with a history of a work-related injury and subsequent anterior cervical diskectomy and fusion from C5 to C7. The patient continued to have persistent pain starting in the thoracic region and radiating down the bilateral lower extremities. MR imaging demonstrated focal dorsal indentation of the spinal cord at T5 with apparent mass effect on the cord. There was mildly increased T2WI signal within the cord immediately cephalad to this level without evidence of syringomyelia formation. The patient subsequently had a T5 laminec- 

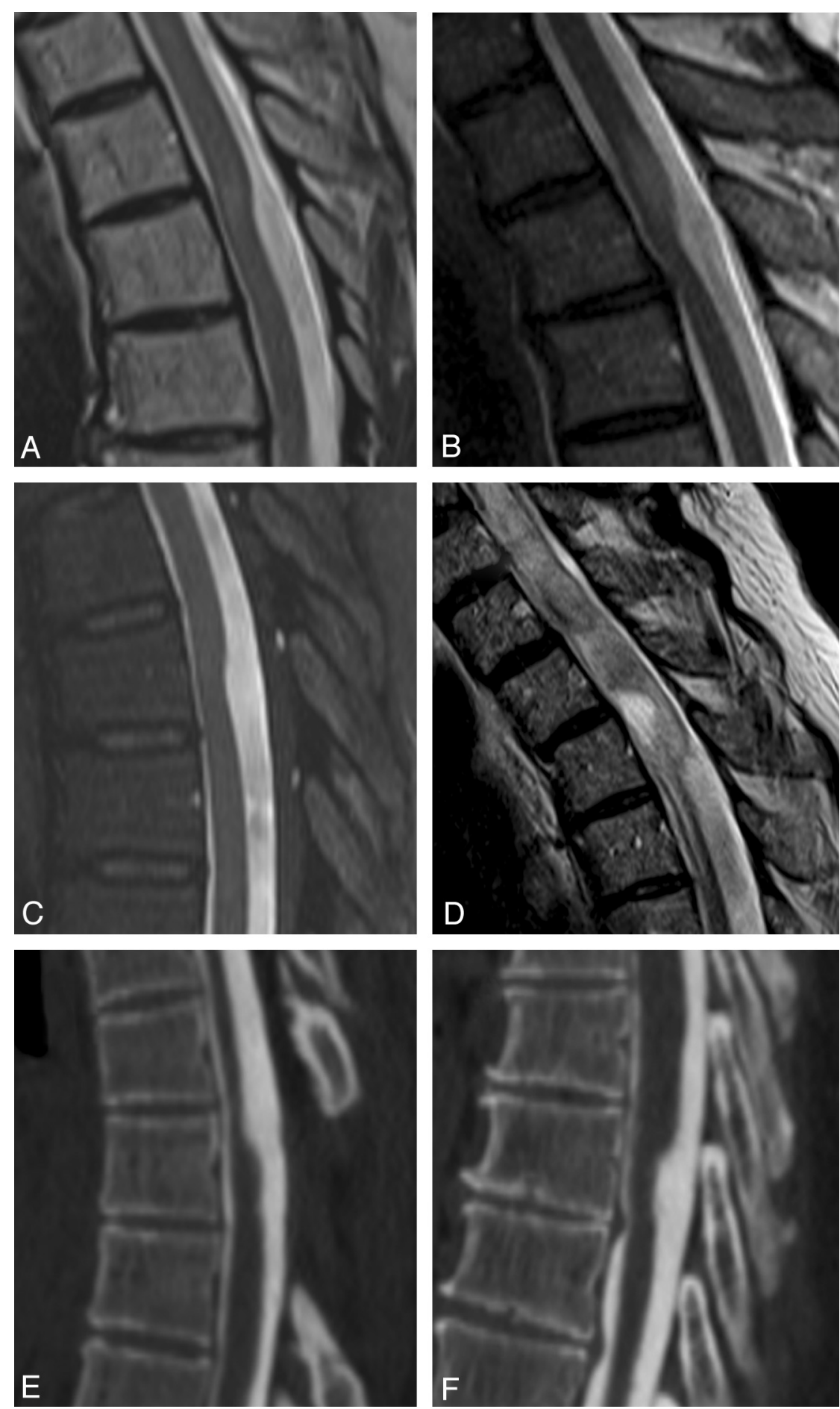

FIG 2. Examples of the dorsal indentation demonstrated in the upper thoracic spine of several patients in the article. $A$ and $B$, Examples of increased cord signal above the level of indentation. C, Dorsal indentation without cord signal changes. D, A case in which there is extensive cord signal change and syringomyelia above the level of indentation. $E$ and $F, C T$ myelograms. $E$, An example of the upside down scalpel sign, where cord expansion occurs inferior to the level of dorsal indentation. Note that previous laminectomies are present in $E$.

tomy, which revealed an arachnoid membrane that was adherent to both the dura and surrounding tissue. After surgical lysis of this band, the patient reported much improved sensation in his lower extremities. Follow-up imaging revealed resolution of the focal cord indentation. There was, however, a focal kinking deformity along the posterior aspect of the cord likely related to postsurgical adhesions to the dorsal dura.

\section{Case 5}

A 56-year-old man with a history of multiple sclerosis was evaluated for a 2-year history of episodic bilateral leg paralysis and falls. Symptomatic episodes occurred without warning, lasted approximately 30 minutes, and were relieved with recumbency. The episodes increased in frequency for 6 months before presentation, at which time these episodes were occurring almost daily. MR im- 
Patient demographics, presenting symptoms, and imaging findings

\begin{tabular}{|c|c|c|c|c|c|c|c|c|}
\hline Patient & $\begin{array}{l}\text { Age } \\
(\mathrm{yr})\end{array}$ & Sex & $\begin{array}{l}\text { Presenting } \\
\text { Symptoms }^{\mathrm{a}}\end{array}$ & $\begin{array}{l}\text { Trauma } \\
\text { History }\end{array}$ & $\begin{array}{c}\text { History of Spine } \\
\text { Surgery }\end{array}$ & $\begin{array}{l}\text { Level of Dorsal } \\
\text { Indentation }\end{array}$ & $\begin{array}{c}\text { Increased T2WI } \\
\text { Cord Signal }\end{array}$ & Syrinx \\
\hline A & 31 & $\mathrm{~F}$ & 9 & No & No & T4 & No & No \\
\hline B & 63 & $M$ & 2 & No & No & $\mathrm{T} 2$ & Yes & Yes \\
\hline$C^{b}$ & 56 & $\mathrm{~F}$ & 2,3 & No & Yes & T6 & Yes & Yes \\
\hline$D^{b}$ & 67 & $M$ & $2,3,7$ & No & No & $\mathrm{T7}$ & Yes & Yes \\
\hline $\mathrm{E}^{\mathrm{b}}$ & 56 & $\mathrm{~F}$ & 2,3 & No & No & T3 & Yes & Yes \\
\hline$F$ & 56 & $F$ & 7 & No & No & $\mathrm{T} 4$ & Yes & No \\
\hline$G^{b}$ & 45 & $M$ & 2,7 & Yes & Yes & T5 & Yes & No \\
\hline $\mathrm{H}$ & 44 & $\mathrm{~F}$ & 7,8 & Yes & No & T4 & Yes & Yes \\
\hline 1 & 44 & $\mathrm{~F}$ & 2,7 & No & No & T6 & No & No \\
\hline $\mathrm{J}^{\mathrm{b}}$ & 51 & $\mathrm{~F}$ & 7,9 & No & No & $\mathrm{T} 4$ & Yes & Yes \\
\hline K & 54 & $M$ & 5,8 & No & No & $T 7$ & $-^{c}$ & $-^{c}$ \\
\hline$L^{b}$ & 54 & $F$ & 8 & No & No & $\mathrm{T} 4$ & Yes & Yes \\
\hline$M$ & 66 & $\mathrm{~F}$ & 7 & No & Yes & $\mathrm{T} 4$ & Yes & No \\
\hline $\mathrm{N}^{\mathrm{b}}$ & 56 & $M$ & 2,3 & No & No & $\mathrm{T7}$ & No & No \\
\hline
\end{tabular}

${ }^{a} 1$ indicates lower extremity pain; 2, lower extremity paresthesia; 3, lower extremity weakness; 4, upper extremity pain; 5, upper extremity paresthesia; 6, upper extremity weakness; 7, back pain; 8, neck pain; 9, shoulder pain.

${ }^{\mathrm{b}}$ Patients who underwent surgery.

${ }^{c}$ Cord signal and syringomyelia could not be assessed because only CT myelography was available for analysis.
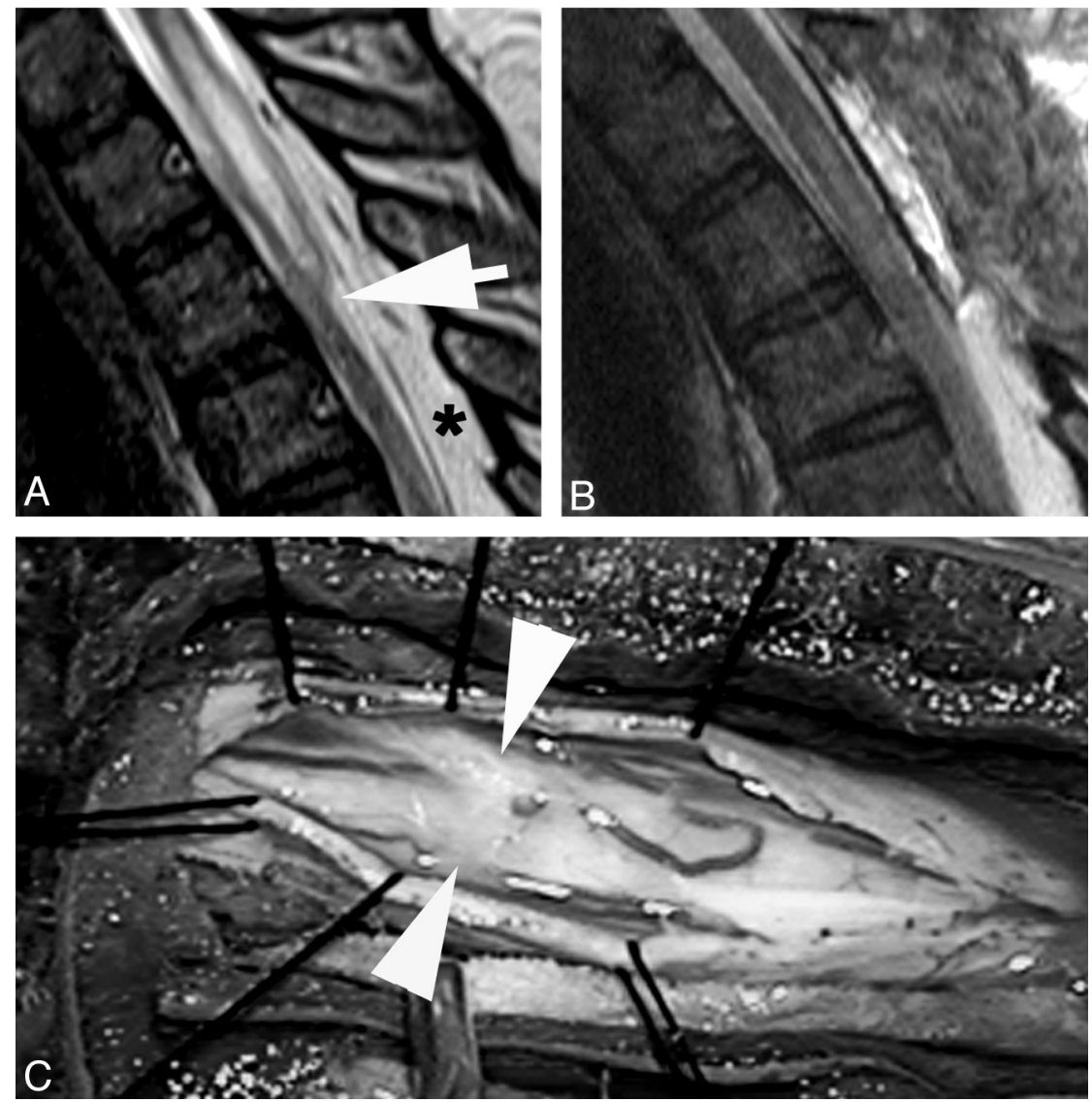

FIG 3. $A, T 2 W I M R$ image demonstrates a focal dorsal indentation in the upper thoracic spinal cord (arrow). Note prominent epidural fat (asterisk). B, T2WI MR image status post-posterior laminectomy and lysis of a dorsal arachnoid web demonstrates resolution of the dorsal indentation, improved cord signal, and resolution of the syringomyelia. $C$, Intraoperative image demonstrates the dorsal arachnoid web (between the white arrowheads) before lysis of the web.

aging of the thoracic spine demonstrated a dorsal indentation of the spinal cord with anterior displacement at the T7 level, without abnormal cord signal or syringomyelia. Subsequently, laminectomies were performed from T5 to T9. When the dura was opened, a dense band of arachnoid tissue was seen extending transversely across the posterior aspect of the spinal cord at the T7 level (Fig 5). This resulted in an obvious deformation of the spinal cord with flattening and compression. The anterior dura was explored, and there was no evidence of a ventral dural defect or anterior cord herniation. Surgical lysis of the arachnoid band was performed, and over several minutes, the cord flattening and deformity visibly improved. The patient's leg strength immediately improved bilaterally with more pronounced improvement on the right. $\mathrm{He}$ continued to have intermittent slight spasticity in both lower ex- 


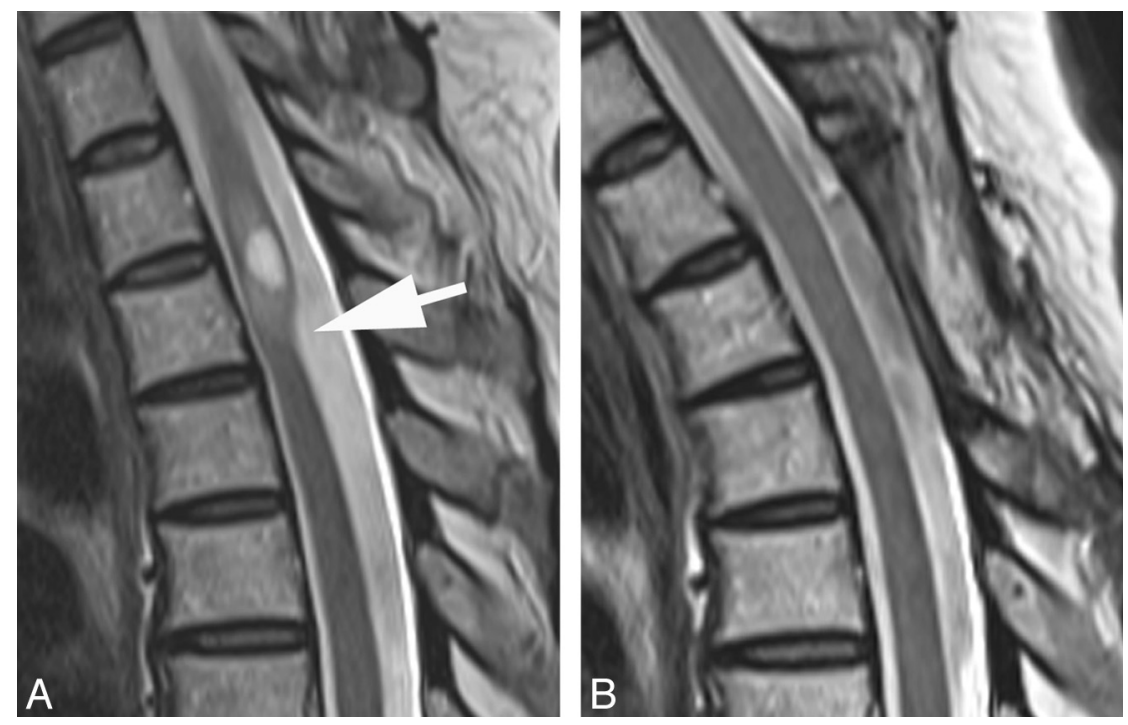

FIG 4. $A, T 2 W I M R$ image demonstrates a dorsal indentation (arrow) and anterior displacement of the upper thoracic spinal cord. Increased cord signal and syringomyelia are present above the level of indentation. B, T2WI MR image status post laminectomy and resection of a posterior arachnoid web demonstrates resolution of the dorsal indentation, cord signal changes, and syringomyelia.
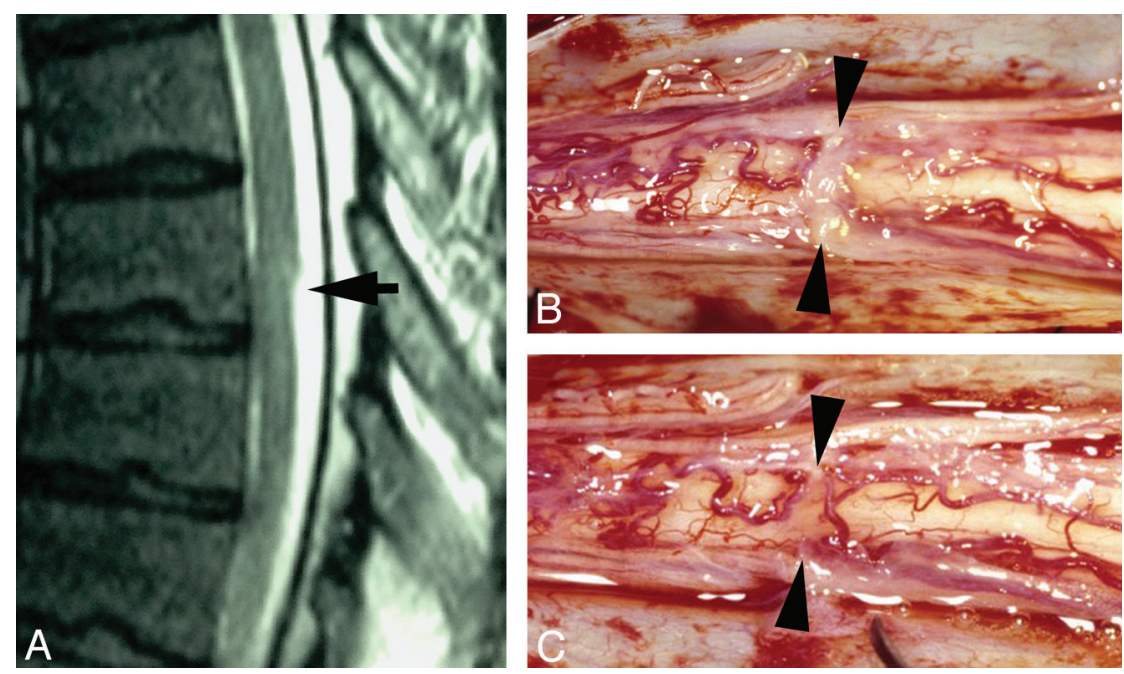

FIG 5. $A$, Sagittal T2WI MR image demonstrates a focal dorsal indentation (arrow) in the thoracic spinal cord. B, Intraoperative image after opening of the dura demonstrates an intradural white arachnoid band (between arrowheads) passing transversely across and compressing the dorsal surface of the spinal cord. C, Intraoperative image of the cord after the band of arachnoid tissue has been cut. The position is marked by arrowheads.

tremities. His coordination slowed when he was fatigued. These symptoms may have been related to his underlying multiple sclerosis. He remained wheelchair-bound, mainly secondary to his lack of coordination. No follow-up imaging was available for this patient.

\section{DISCUSSION}

The exact etiology of arachnoid webs is uncertain. The 5 surgically confirmed cases described in this article, and the 6 prior case reports all demonstrated a dorsal location in the thoracic spine. Their common dorsal location in the upper thoracic spine suggests that these webs share a common etiology. The reason for the predilection for the upper thoracic spine is unknown. One case report suggested that this dorsal location may be related to the theory of arachnoid cyst formation from diverticulations of the septum posticum, a thin membrane that longitudinally divides the posterior subarachnoid space. ${ }^{3,4}$ Several reports have described intradural arachnoid cysts and their associated mass effect on the spinal cord. ${ }^{5-8}$ Arachnoid webs may represent the incomplete or disrupted formation of an arachnoid cyst. It is also conceivable that a web may actually be comprised of the walls of a collapsed arachnoid cyst.

There appears to be a relationship between the presence of a dorsal arachnoid web and syringomyelia. The 6 previously reported cases demonstrated syringomyelia adjacent to the level of cord indentation, 5 below and 1 above the level of the indentation. ${ }^{1-3}$ Syringomyelia was present in 7 patients in our study, 6 above and 1 below the level of dorsal indentation. There is a probable spectrum of cord signal-intensity changes on MR imaging, from a presyrinx state to the development of syringomyelia. The 

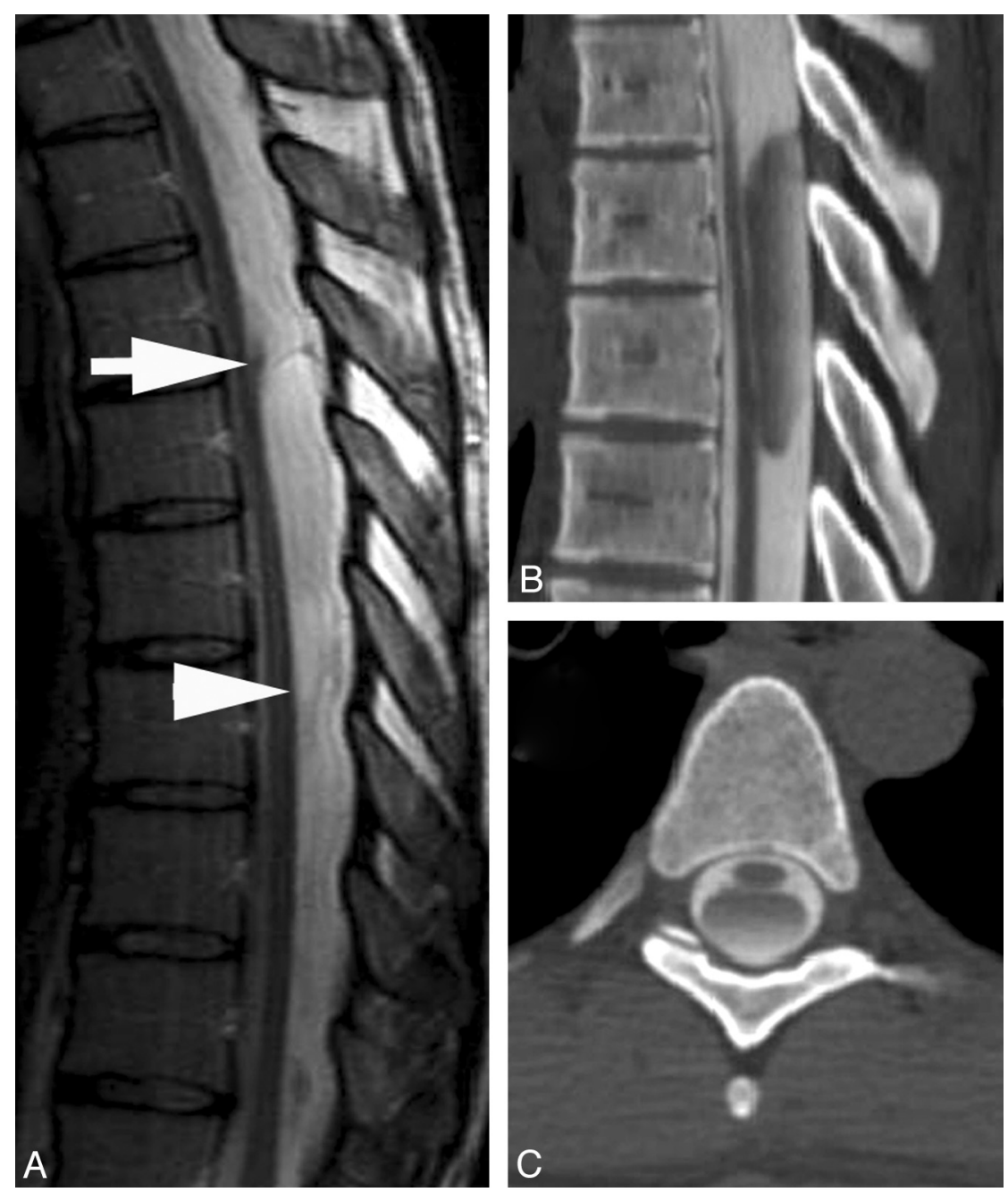

FIG 6. A, Sagittal T2WI MR image demonstrates a typical intraspinal extramedullary arachnoid cyst. Superior and inferior aspects of the cyst are delineated by the arrow and arrowhead, respectively. B and C, Sagittal and axial CT myelograms show how the arachnoid cyst fills more slowly than the CSF after intrathecal contrast injection.

case report by Sridharan and Heilman ${ }^{1}$ suggested that the determining factor for syringomyelia formation above or below the level of an arachnoid web is related to the CSF pressure differential on either side of the web. A greater CSF pressure rostrally would result in syringomyelia formation caudal to the web and vice versa. This relates to the intramedullary pulse pressure theory of syringomyelia formation, in which a lower CSF pressure on one side of a subarachnoid obstruction leads to cord distension during each systole via a suction effect from the gradient pressure differential, which causes CSF to enter the cord through small perivascular spaces. ${ }^{9}$

While none of the cases described in this study utilized cine MR imaging, we recognize that being able to analyze CSF flow dynamics could be valuable in the evaluation of arachnoid webs. Cine MR imaging is essential in the pre- and postsurgical management of patients with Chiari I with syringomyelia. ${ }^{10}$ In a similar manner, we hypothesize that arachnoid webs may demonstrate an alteration in CSF flow in the dorsal subarachnoid space. Pre- and postoperative imaging could also allow analysis of improved CSF flow after web lysis.

The differential diagnosis of the scalpel sign is a dorsal arach- noid web, dorsal arachnoid cyst, and ventral spinal cord herniation. Spinal cord herniation can often be distinguished from an arachnoid cyst or web on routine imaging. In cord herniation, cord tissue protrudes through a ventral dural defect, and the focal deformity along the ventral aspect of the cord is often demonstrated. However, when the ventral spinal cord is closely opposed to the anterior dura, it may be difficult or impossible to distinguish a dorsal arachnoid web and anterior spinal cord herniation. Arachnoid cysts can be identified by the marginated walls, the presence of smooth wide scalloping of the cord surface, and the fact that these structures routinely fill slower than the remainder of the subarachnoid space on myelography (Fig 6). Seven patients in our study underwent myelography, with no arachnoid cyst identified. Arachnoid webs, however, are not usually directly demonstrated on MR imaging or CT myelography. Only 1 of 6 prior cases reported preoperative demonstration of the web on MR imaging, and none of our cases had a visible web or membrane on imaging. The scalpel sign appears to be an important secondary imaging sign that suggests the presence of an arachnoid web.

The retrospective nature of this study is a limitation, and only

AJNR Am J Neuroradiol 34:1104-10 May 2013 www.ajnr.org

1109 
5 of our 14 cases were surgically confirmed. Therefore, we do not have surgical proof in 9 of our cases that an arachnoid web was the cause of the scalpel sign and cord signal changes. However, on the basis of imaging from the surgically confirmed cases that we have collected, an arachnoid web appears to be the most likely diagnosis.

\section{CONCLUSIONS}

It is important that radiologists recognize the scalpel sign. Of the 5 patients who had surgical lysis of an arachnoid web, all reported improved symptoms postoperatively, and the follow-up MR imaging, available in 4 of the 5 cases, demonstrated significant improvement in the cord appearance. Likewise, failure to recognize this new radiographic sign may result in delay of treatment and worsening of spinal cord function. If a web is not considered preoperatively, shunting of the syrinx alone or even cord biopsy may be erroneously performed, leaving the primary cause of the cord abnormality untreated. The scalpel sign suggests the existence of a dorsal arachnoid web and should prompt surgical consultation for possible lysis of the web, with or without shunting of the syrinx.

Disclosures: Justin S. Smith—UNRELATED: Consultancy: Biomet Spine, DePuy Spine, Medtronic, Grants/Grants Pending: American Association of Neurological Surgeons (AANS)/CNS Spine Joint Section, * Payment for Lectures (including service on Speakers Bureaus): Biomet Spine, DePuy Spine, Medtronic, Globus, Travel/Accommodations/Meeting Expenses Unrelated to Activities Listed: Association for Collaborative Research, Other: DePuy Spine, ${ }^{*}$ Comments: research study group support. Mark E. Shaffrey-UNRELATED: Expert Testimony: brain tumor case not connected in any way with the article.* Christopher I. Shaffrey-UNRELATED: Board Membership: AANS, Scoliosis Research Society, Journal of Neurosurgery, Neurosurgery, Spine, Spine Deformity, Consultancy: Biomet, DePuy, Globus, Medtronic, NuVasive, Expert
Testimony: various cases all paid to the University of Virginia, ${ }^{*}$ Grants/Grants Pending: National Institutes of Health, ${ }^{\star}$ Department of Defense, ${ }^{*}$ North American Clinical Trials Network, * DePuy, ${ }^{\star}$ AO North America, * Payment for Lectures (including service on Speakers Bureaus): Globus, NuVasive, Patents (planned, pending, or issued): Biomet, ${ }^{*}$ Medtronic, ${ }^{\star}$ Royalties: Medtronic,* Payment for Development of Educational Presentations: Globus, DePuy, Medtronic, NuVasive. Max Wintermark—UNRELATED: Grants/Grants Pending: GE Healthcare, * Philips Healthcare. * *Money paid to the institution.

\section{REFERENCES}

1. Sridharan A, Heilman CB. Transverse dorsal arachnoid web and syringomyelia: case report. Neurosurgery 2009;65:E216-17

2. Brodbelt AR, Stoodley MA. Syringomyelia and the arachnoid web. Acta Neurochir (Wien) 2003;145:707-11, discussion 711

3. Paramore CG. Dorsal arachnoid web with spinal cord compression: variant of an arachnoid cyst? Report of two cases. J Neurosurg 2000;93:287-90

4. Perret G, Green D, Keller J. Diagnosis and treatment of intradural arachnoid cysts of the thoracic spine. Radiology 1962;79:425-29

5. Holly LT, Batzdorf U. Syringomyelia associated with intradural arachnoid cysts. J Neurosurg Spine 2006;5:111-16

6. Takeuchi A, Miyamoto K, Sugiyama S, et al. Spinal arachnoid cysts associated with syringomyelia: report of two cases and a review of the literature. J Spinal Disord Tech 2003;16:207-11

7. Wang MY, Levi $\mathrm{AD}$, Green BA. Intradural spinal arachnoid cysts in adults. Surg Neurol 2003;60:49-55

8. Petridis AK, Doukas A, Barth H, et al. Spinal cord compression caused by idiopathic intradural arachnoid cysts of the spine: review of the literature and illustrated case. Eur Spine J 2010;19(suppl 2):S124-29

9. Greitz D. Unraveling the riddle of syringomyelia. Neurosurg Rev 2006;29:251-63

10. Ventureyra EC, Aziz HA, Vassilyadi M. The role of cine flow MRI in children with Chiari I malformation. Childs Nerv Syst 2003;19: $109-13$ 